\title{
¡Esto no será un sindicato de alcaldes, pero...! \\ Repensando la intermediación local-nacional a través de la historia de la Asociación Chilena de Municipalidades 1993-2005
}

\author{
This will not be a union of mayors, but ...! \\ Rethinking local-national mediation through the history of the \\ Chilean Association of Municipalities 1993-2005.
}

\begin{abstract}
Aníbal Pérez Contreras*
Resumen: El presente artículo analiza la erosión del sistema de intermediación localnacional para el periodo postdictatorial chileno. La hipótesis principal sostiene que, desde un punto de vista histórico, dicha fractura fue fruto del desarrollo de una estrategia dual de parte de los alcaldes, quienes ocuparon métodos gremiales mediante la Asociación Chilena de Municipalidades, así como también lobby intra-partidario, generando diferentes tensiones. Con ello evaluamos los alcances y límites que supuso la alcaldización de la política, así como la diferencia que implicó el modelo propuesto por Arturo Valenzuela para el periodo previo a 1973.
\end{abstract}

Palabras clave: Municipios, clientelismo, intermediación política, postdictadura.

\begin{abstract}
The present article analyzes the erosion of the local-national intermediation system for the Chilean post-dictatorial period. The main hypothesis is that, from a historical point of view, this fracture was the result of the development of a dual strategy by the mayors, who used union methods through the Chilean Association of Municipalities, as well as intra-party lobbying, generating different tensions. With this, we evaluated the scope and limits of the municipalization of the policy, in addition to the difference that the model proposed by Arturo Valenzuela represented for the period prior to 1973.
\end{abstract}

Keywords: Local government, clientelism, brokerage, post-dictatorship.

Recibido: 30 diciembre 2018 Aprobado: 24 febrero 2019

\footnotetext{
* Chileno. Doctor (C) en Historia, departamento de historia, Universidad de Santiago de Chile. Investigador asociado Centro de Estudios de Historia Política, Escuela de Gobierno, Universidad Adolfo Ibáñez, anibal.perez@,usach.cl. Becario Conicyt n²1170370. Agradecemos al proyecto Fondecyt Regular n¹160984 al cual adscribimos como tesista doctoral.
} 


\section{Introducción}

En plena campaña presidencial del año 2017, un popular alcalde de derecha reconocía vía entrevista radial la exigencia de votos que desde su conglomerado les habían puesto a los ediles para las primarias venideras, ante lo cual sentía una fuerte responsabilidad sobre sus hombros. Tiempo más adelante y en la vereda de enfrente, el equipo del candidato Alejandro Guillier se veía en la necesidad de solicitar a los ediles su compromiso con la centro-izquierda, pues la posibilidad de la derrota rondaba en sus calculadoras ${ }^{1}$. Tras el triunfo presidencial de Sebastián Piñera, otro popular alcalde de Chile Vamos, señalaba que en primera vuelta los ediles de su sector estuvieron trabajando en las campañas de CORES, diputados y senadores, en cambio en el balotaje se concentraron en la presidencial, lo que explicaría el aumento de preferencias. Además, puntualizó: "cuando en segunda vuelta salí a hacer campaña por el presidente, le pedí a los vecinos su confianza dándole el voto a Piñera". Más adelante el periodista le preguntó sobre su disponibilidad para un cargo en el nuevo gobierno, ante lo cual la respuesta del líder local fue clara: "mi responsabilidad es con los habitantes de mi localidad. Y lo único que quiero es que se cumplan los compromisos que se adquirieron con la comuna, que son la extensión del Metro, la entrega de más recursos para enfrentar la delincuencia y la construcción de los hospitales que tanto necesitamos" 2 . En otras palabras, el edil recordaba la necesidad de cumplir con el circulo de la reciprocidad, pues también tenía que rendir cuentas con sus clientelas locales, sobre las cuales radicaba la esperanza en la obtención de recursos para diferentes obras comunitarias. ¿Qué tan nueva ha sido esta práctica en el sistema de partidos chileno? ¿En qué consistió el trabajo político de los alcaldes durante la posdictadura? Y ¿de qué manera se fue configurando la intermediación de demandas locales para la extracción de recursos desde el centro? En un canónico estudio para el periodo anterior a 1973, Arturo Valenzuela explicó el funcionamiento del sistema de intermediación chileno, en cuya base los alcaldes contribuían en la construcción de clientelas electorales locales para poner a disposición de los comicios nacionales a cambio del compromiso de inversión de recursos en la arena local. ¿Qué ocurrió con dicho sistema en el periodo postdictatorial? Es la problemática sobre la que reflexionamos. Para esto, el presente artículo historiza el andamiaje del sistema anteriormente descrito, es decir, los ediles en el periodo 1993-2005 a través del nacimiento y desarrollo del "gremio de alcaldes": la Asociación chilena de Municipalidades. Con esto, se estudia la actuación de los líderes locales durante distintas coyunturas políticas, tanto nacionales como de interés corporativo.

A modo de hipótesis, sugerimos que los efectos de la reforma municipal del régimen militar potenciaron las capacidades clientelares de los alcaldes, quienes asumieron una estrategia dual, caracterizada por la mantención de sus redes en los partidos y al mismo tiempo la generación de una plataforma corporativa en la ACHM. No sin conflictos, esto implicó el desarrollo de demandas enfocadas en la elección directa de autoridades, mayores recursos, más autonomía y atribuciones, debilitando así el sistema de intermediación local-nacional que antes estuvo subordinado a los partidos 3 . A pesar de esto, el límite de la alcalización y empoderamiento radicó en la mantención del sistema electoral, lo que obligó a los ediles que pretendían continuar con sus carreras a tender redes hacia "arriba" de sus agrupaciones.

\footnotetext{
${ }^{1}$ La Tercera, 17 de noviembre de 2017.

${ }^{2}$ La Tercera, 1 de enero de 2018.

3 Por intermediación política entendemos las practicas que conllevan la construcción de lazos bajo la porosa relación entre sociedad y Estado. Generalmente es pensado para comunidades locales hacia el resto del sistema. A su vez, su relación localnacional se refiere a articulación entre las dos escalas mencionadas, mientras que para el caso de los alcaldes y sus potencialidades clientelares nos referimos a mediación personalizada. Para ello ver: Turid, Hagene, "Political Clientelism in Mexico: Bridging the Gap between Citizens and the State", Latin American Politics and Society, 57, 1, 2015, pp. 139-162. doi:10.1111/j.15482456.2015.00259.x, Evelyn Arriagada, "Clientelismo político y participación local”, Polis, 36, Santiago, 2013, disponible en: http://journals.openedition.org/polis/9389
} 
Es decir, no bastó con el empoderamiento territorial ${ }^{4}$. El análisis histórico está articulado en dos fases, la primera (1993-1997) evalúa los logros de las demandas en los tres objetivos macros desarrollados por la agrupación: elecciones directas y separadas; más atribuciones (descentralización) y más recursos. En el segundo ciclo (1998-2005), se da cuenta de los conflictos internos en la asociación, así como el cambio de escenario histórico y los resultados a partir de los objetivos anteriormente señalados. Más que imponer una temporalidad macro hacia nuestro objeto de estudio, sugerimos adecuarnos a la suya propia, desplegada al calor de su tridente ofensivo: recursos, poder y democracia. Por ello el trabajo se abre en 1993 (año de fundación de la asociación) y se cierra en 2005 cuando se aprueba la Ley de Rentas II, permitiendo un análisis de ciclo completo desde el tiempo de la propia asociación al calor de sus logros y fracasos con los propios objetivos. En este sentido, el presente artículo no es un análisis del funcionamiento de los municipios, sino más bien una historia social y política de su agrupación gremial junto a sus efectos para el sistema de intermediación durante la transición chilena.

Metodológicamente, se recurrió a revisión de prensa nacional y local: Revista Ercilla, Actual, diarios: La Tercera, La Nación, El Siglo, El Mercurio de Valparaiso, el Sur de Concepción 1992-2005, las Memorias de la Asociación Chilena de Municipalidades (1995-2007), además de: Historia de la Ley n ${ }^{\circ}$ 19.280, Historia de la Ley no 19.483 e Historia de la ley no 20.033 .

\section{1.- Antecedentes históricos y debates sobre el rol de los alcaldes en la transición.}

En su tesis doctoral "Intermediarios políticos en Chile" Arturo Valenzuela describió de manera magistral las características del icónico sistema de partidos chileno. Definido por su carácter dual, por una parte, se observaba un esquema de tres tercios tendientes a la polarización, con actores políticos orientados en construcciones ideológicas más menos coherentes, incluido, a partir de la década del sesenta, la erosión de un centro pragmático capaz de llegar a acuerdos con los extremos del sistema. Sin embargo, por otra parte, observó un segundo canal no menos importante de la estructura política, según la cual el sistema absorbía demandas particularistas desde las periferias hacia el centro. Ello se estructuraba en razón de clientelas locales que poseían alcaldes y regidores en los municipios, las que se ponían a disposición de los candidatos parlamentarios bajo el compromiso de extraer recursos hacia las provincias, mediante indicaciones durante las discusiones presupuestarias anuales. En esto los ediles jugaban el rol de verdaderos mediadores parlamentarios, pues articulados a través de sus redes partidarias, lograban transacciones de sus demandas locales para solucionar problemas vía intra-sistema instalando su capital social para la expectativa de la movilización electoral posterior. A nuestro juicio, los grados de autonomía que poseían los mediadores tenían límites claros radicados en un sistema de partidos fuerte, lo que evitó la fuga masiva de las redes partidarias a través de posibles plataformas gremiales o corporativas. De hecho, el propio autor señaló que el canal oficial y estructural de estas demandas eran los propios partidos políticos. Allí radicaba la fortaleza del sistema, pues hasta en el último rincón del territorio los candidatos se subsumían a los conglomerados. Por precarias que hayan sido, los partidos contaban con sedes propias y presencia, especializándose en la costumbre, como un verdadero arte, de hacer pequeños favores a sus electores $^{5}$.

Instaurada la dictadura militar, una de las mayores preocupaciones de las autoridades era precisamente el exceso de politización en la ciudadanía, lo que llevó a las mismas a concentrarse en un esfuerzo para re-socializar al pueblo de Chile. A fin de esto, según lo ha demostrado Verónica Valdivia, el régimen propuso una reforma municipal que desarticulara las antiguas funciones del Estado en el

${ }_{4}$ Peter, Siavelis, "The Hidden Logic of Candidate Selection for Chilean Parliamentary Elections", Comparative Politics, 34, 4, New York, 202, 419-438, Vicente Espinoza y Sebastián Madrid, Trayectoria y eficacia política de los militantes en juventudes políticas. Estudio de la elite politica emergente, Santiago, CEP, Proyectamerica, LYD, CIEPLAN, IDEA, USACH, Santiago, 2010.

5 Arturo, Valenzuela, Political borkers in Chile, Durham, N.C., Duke University Press, 1977. 
gobierno local (como educación y salud) a fin de potenciar la figura del edil como el mejor asignador de recursos. Esto, desde una clave apolítica y tecnocrática, permitiría desdibujar los lugares tradicionales de la política como el Parlamento y los partidos, potenciado las capacidades clientelares de un alcalde "todo poderoso" que mantendría un contacto predilecto con la ciudadanía, al mismo tiempo que abría paso a un proceso de descentralización en lógica neoliberal ${ }^{6}$.

Tras el retorno de la democracia las potencialidades clientelares de los alcaldes han sido abundantemente analizadas desde diversas perspectivas, así como en distintos casos del territorio nacional7. A nuestro juicio, visto "desde abajo", lo que ha operado en estas redes es una costumbre política regulada por una economía moral de los actores, articulada en la expectativa de la reciprocidad electoral a cambio de distribución de favores tanto individuales como colectivos ${ }^{8}$. Por otro lado, sobre estos nuevos alcaldes empoderados se ha desarrollado un debate con posiciones no del todo excluyentes,

"Verónica, Valdivia, "Al rescate del municipio. La síntesis ideológica de la dictadura pinochetista", Observatorio Latinoamericano,
Dossier Chile, Buenos Aires, 2011, Verónica Valdivia, Rolando Alvarez y Karen Donoso, La alcaldización de la política, LOM
Ediciones, Santiago, 2012. La potente densificación de atribuciones municipales chilena difiere de casos como Argentina, donde
la paulatina descentralización del Estado fue desgranándose en funciones asignadas en los gobiernos federales y provinciales. Sin
embargo, atribuciones como la seguridad ciudadana y el rol de primer anillo con la ciudadanía son coincidentes. Para ello ver:
Daniel, Cravacuore, "Los municipios argentinos (1990 - 2005)", en: Cravacuore e Israel, R. (comp.) Procesos políticos municipales
comparados en Argentina y Chile (1990 - 2005), Editorial de la Universidad Nacional de Quilmes - Universidad Autónoma de Chile.
Buenos Aires, 2007, pp. 25 a 49, Horacio, Cao, "La administracio $\square$ n pu $\square$ blica argentina: nacio $\square$ n, provincias y municipios",
XIII Congreso Internacional del CLAD sobre la Reforma del Estado y de la Administracio $\square \mathrm{n} \mathrm{Pu}$ blica, Buenos Aires, 2008, disponible en: https://www.horaciocao.com.ar/wp-content/uploads/2015/06/40-la-administracion.pdf

${ }^{7}$ Emmanuelle, Barozet, "La compra de los votos en Chile o cómo se coopta a los sectores populares", Contribuciones cientificas y tecnológicas, 33,133, Santiago, 2000, 10-13, Barozet, "Movilizacio $\square$ n de recursos y redes sociales en los neopopulismos: hipo $\square$ tesis de trabajo para el caso chileno", Revista de Ciencia Pol $\square$ tica, 23, 001, Santiago, 2003, 39-54, Barozet, "Elementos explicativos de la votacio $\square$ n de los sectores populares en Iquique: lo $\square$ gica y eficiencia de las redes clientelares", Pol $\square$ tica, 043, 2004, Santiago, 205-251, Barozet, "Populismo regional y Estado: el caso de Chile", Estudios Interdisciplinarios de América Latina y el Caribe 19 (2), Tel Aviv, 2007, 45-60, disponible en: http:/ /repositorio.uchile.cl/handle/2250/121534, John Durtson, Daniel Duhart, Francisca Miranda, Evelyn Monzó, Comunidades campesinas, agencias públicas y clientelismos políticos en Chile, LOM Ediciones, Santiago, 2005, Evelyn Arriagada, "UDI: ¿partido popular o partido populista? Consideraciones sobre el éxito electoral del Partido Unión Demócrata Independiente en los sectores populares", Colección Ideas, 6, 51, Santiago, 2005, Arriagada, "Neopopulismo y clientelismo en la derecha chilena. La inserción de la UDI en una comuna popular del Gran Santiago", Memoria para optar al título profesional de antropóloga en Universidad de Chile, Santiago, 2008, Arriagada, "Clientelismo político y participación local “, Polis, 36, Santiago 2013, disponible en: http://journals.openedition.org/polis/9389, Verónica, Valdivia, "El Santiago de Ravinet. Despolitización y consolidación del proyecto dictatorial en el Chile de los noventa”, Historia, 46, Santiago, 2013 177219. Disponible en: <https://scielo.conicyt.cl/scielo.php?script=sci_arttext\&pid=S071771942013000100006\&lng=es\&nrm=iso >. ISSN 0717-7194. http://dx.doi.org/10.4067/S0717-71942013000100006, Valdivia, "La alcaldía de Joaquín Lavín y el lavinismo político en el Chile de los noventa", Historia Política, Buenos Aires, 2012, disponible en: <http://historiapolitica.com/datos/biblioteca/chile_ ortizdezarate.pdf>, Aníbal, Pérez, "Clientelismo político, neoliberalismo y la Concertación: El guatón Pinto en el municipio de Valparaíso, 1990-1996”, Divergencia, 2, 3, Valparaíso, 2013, 89-113, Pérez, "¿UDI popular? Los campamentos y el respaldo electoral-popular de derecha. El caso de Virginia Reginato en Viña del Mar (2008-2013)”, Izquierdas, 21, Santiago 2014, 1-30, Pérez, La UDI tras el telón. Agitación social, lavinismo y clientelismo, Editorial América en Movimiento, Valparaíso, 2016, Pérez, "Más allá de la excepcionalidad. Clientelismo político en Chile: debates, antecedentes históricos y algunos rasgos generales en el tiempo presente", en Itinerarios políticos contemporáneos en Argentina, Brasil, Chile y Uruguay, compilado por Pinillos, C.; Cavarozzi, M. y Mella Polanco, M. UNR Editora, Rosario, 161-182, David, Lujan, "Entre la autonomía y la dependencia. Lobby, clientelismo político e idea de estado en los contextos locales chilenos", Polis, 16, 48, Santiago, 2017, 133-154, Luján y Pérez, 'La Democracia Cristiana en el 'área chica' de la posdictadura chilena. Prácticas políticas y relaciones clientelares en una comuna chilena”, Íconos FL ACSO-Ecuador, 60, 2018, 153-163, Luján y Pérez, "Cercanía, favor, lealtad. Clientelismo en dos municipalidades chilenas", Sociológica, 33, 94, México D.F., 2018, 235-268, Rolando Álvarez, "Clientelismo y mediación política: Los casos de los municipios de Renca y Huechuraba en tiempos de la 'UDI Popular", Divergencia, 6, Valparaíso, 2016, 41-53, Juan Pablo Luna, "Segmented party-voter linkages in Latin America: the case of the UDI", Journal of Latin American sutdies, 42, 2010, 325-356.

8 Aníbal, Pérez, "En el canto del Estado. Del clientelismo programático al clientelismo neoliberal", en Transiciones. Perspectivas historiográficas sobre la postdictadura chilena, 1988-2018, José Ponce, Aníbal Pérez y Nicolás Acevedo compiladores, Editorial América en Movimiento, Valparaíso, 2018. 
en torno al significado e implicancias de la emergencia de figuras políticas, cuyas plataformas se han sustentado en el espacio local, ya sea para constituirse en fenómenos regionales o para dar el salto a la política nacional ${ }^{9}$. Por una parte, este tipo de liderazgos han sido categorizados como fenómenos neopopulistas, en un concierto internacional que mostraba la emergencia de líderes particulares como Fujimori, Menem, Macri o el propio Giulliani. De hecho, para el caso nacional las figuras como Soria en Iquique y Lavín en Santiago han sido categorizadas como tales, así como también la propia UDI ${ }^{10}$. Por otro lado, desde una óptica más histórica, se ha recurrido a la noción de alcaldización, como fruto del proyecto dictatorial descrito más arriba. En este sentido, el fenómeno representaría la continuidad histórica del legado dictatorial, encarnado en el ADN de la Unión Demócrata Independiente cuya figura más relevante hasta entrados los años 2000 fue Joaquín Lavín y su estilo "lavinista"11. Esta segunda mirada no sería del todo excluyente con la primera, sólo que pondría su eje de análisis en una temporalidad mayor adentrándose en las causas de la emergencia de los fenómenos llamados primeramente por algunos autores como neopopulistas ${ }^{12}$.

Desde la óptica de este trabajo, la emergencia de estos tipos de liderazgos locales se explicaría en razón del dislocamiento que fue surgiendo en el sistema de intermediación local nacional a partir de la transición, diferenciándose del que describió Arturo Valenzuela para la década del sesenta. Coincidimos por tanto con lo planteado por Luna y Mardones ${ }^{13}$ y enunciado tempranamente por Rehren y luego Espinoza ${ }^{14}$, en tanto que dicha estructura sufrió un proceso de fractura debido entre otras cosas, al debilitamiento de los partidos como columna vertebral del sistema. Sin embargo, a nuestro juicio otro factor que aportó en dicha dislocación, fueron los efectos que implicó una reforma municipal de la dictadura militar carente de los recursos necesarios para las nuevas tareas de los gobiernos locales, dando paso a la continuidad del histórico Estado centralista chileno. ${ }^{15}$ Esto terminó impulsado la organización de los ediles en la asociación, modificando el rol de intermediación parlamentario del sistema hegemonizado por los partidos. Siguiendo a Sergio Toro, el nuevo escenario transicional dio paso a un tipo de broker burocrático de carácter más autorreferencial, quienes tendieron a la acumulación capital político para sí mismos, haciendo más difícil el traspaso de votos intra-partido ${ }^{16}$. Además, otra de las consecuencias que produjo la reforma fue la modificación del financiamiento municipal, el que entró en

\footnotetext{
9 Para ver el fenómeno de alcaldes independientes de los partidos políticos ver: Tomás, Dosek, "La presencia y el éxito de los independientes en las elecciones municipales en Chile (1992-2012), en: Luna y Mardones, op.cit. 2017.

${ }^{10}$ Barozet, op.cit. 39-54, Arriagada, op.cit, 2008, Luis, Corvalán, Del anticapitalismo al neoliberalismo en Chile, Editorial Sudamericana, Santiago, 2003.

11 Valdivia, op.cit. 2012; Valdivia, Verónica Valdivia, La "alcaldización de la política” en la post dictadura pinochetista. Las comunas de Santiago, Las Condes y Pudahuel, Irquierdas 38, febrero 2018:113-140

12 Para el concepto de neopopulismo ver: Kenneth, Roberts, "El neoliberalismo y la transformacio $\square$ n del populismo en Ame $\square$ rica latina. El caso peruano", en: Mackinnon, Mari $\square$ a yetrone, Mario (Eds.), Populismo y Neopopulismo en Ame rica Latina. El problema de la Cenicienta, EUDEBA, Buenos Aires, 1999. pp. 375 - 408.

13 Juan Pablo Luna y Rodrigo, Mardones, La columna vertebral fracturada, RIL Editores, Santiago, 2017.

14 Rehren, Alfredo "El impacto de las poli $\square$ ticas autoritarias a nivel local: implicancias para la consolidacio $\square$ n democra $\square$ tica en Chile", Santiago, Estudios Pu $\square$ blicos, No.44, 1991, Vicente, Espinoza, "Los nuevos Agentes Políticos Locales: Revisión Estructural de la Tesis de Arturo Valenzuela ¿Cómo se articulan el nivel de representación local con el nacional en la arena local y qué papel juegan el gobierno central y las políticas públicas?” Revista Mad.,14, Departamento de Antropología, Universidad de Chile, Santiago, 2006, disponible en: http://www.revistamad.uchile.cl/14/espinoza.pdf .

15 Este fenómeno ha sido conceptualizado por Esteban Valenzuela como presicrático, es decir presidencialista y centralista. Para ello ver: Valenzuela y Yévenes, “Aproximación al concepto de cooptación política: la maquinaria presicrática y sus formas”, Polis, 14, 40, 2015, pp. 469-488, disponible en: https://scielo.conicyt.cl/pdf/polis/v14n40/art22.pdf, Esteban, Valenzuela, "Despoder y progresismo federalistafraterno para superar la izquierda presicrática", Polis, 16, 46, 2017, pp. 127-148, disponible en: https://scielo.conicyt.cl/pdf/polis/v16n46/0718-6568-polis-16-46-00127.pdf, Ortiz y Valenzuela, "Chile, un siglo de pugna por la democratizacio $\square$ n de las regiones. Representacio $\square$ n minimizada y centralismo transversal”, Estudios Poli $\square$ ticos, 52, 2018, pp. 36-56, disponible en: http://www.scielo.org.co/pdf/espo/n52/0121-5167-espo-52-00036.pdf

16 Sergio, Toro, "El vínculo distrital de los parlamentarios: continuidad y cambio de la estructura de intermediación local en Chile”, en: Luna y Mardones, La columna vertebral fracturada, RIL Editores, Santiago, 2017.
} 
una fase de auto-generación presupuestaria, al que se le apoyó con la creación de Fondo Común Municipal, junto a otras vías de financiamiento del nivel central, ya fuese vía SUBDERE o FNDR. Todo lo anterior en un contexto internacional que mostraba el desplome de la Guerra Fría y la pérdida de la capacidad agonista de la política interna.

Ahora bien, dicha fractura no fue de un momento a otro, sino que tuvo su propia historicidad marcada en los actores principales del fenómeno, es decir los alcaldes y su Asociación. ¿De qué manera se desarrolló esta historia? A nuestro juicio mediante una estrategia dual de los ediles, quienes, mientras siguieron militando en sus partidos y asegurando con ello sus cupos electorales, desplegaron una plataforma más "gremial" en la ACHM. De esta forma, su trabajo político ${ }^{17}$ cotidiano consistió en militar al mismo tiempo en sus propios partidos como en su actividad gremial. Además, en continuidad con las prácticas pre-1973, fueron personificando el vínculo social con los territorios recurriendo a redes clientelares. Claro está, el límite en sus pretensiones de ascenso político estuvo radicado en los partidos, los cuales siguieron manteniendo el monopolio de la inscripción de candidaturas generando con ello diferentes tensiones.

\section{2.- Nace el gremio de alcaldes. Primera temporalidad 1993-1997.}

El 8 de mayo de 1993 bajo el plenario de Congreso Nacional el vicepresidente de la República, Enrique Krauss, entregó claras advertencias sobre el sentido, límites y la dirección que debería tomar la naciente agrupación de ediles para que no se transformara en un instrumento de poder desestabilizadores de la política nacional en materia municipal: "si esto sucediera -y estoy seguro que así no va a ser- constituiría un motivo de defraudación moral respecto de una comunidad que confía en ustedes..."18. En respuesta, el flamante presidente electo por aclamación popular, Jaime Ravinet, respondió que la agrupación no se convertiría en un sindicato de alcaldes; habló de los problemas externos, las leyes y los déficits que significaban los servicios traspasados de salud y educación que ascendían a 28 mil millones de pesos. A esto solicitó el traspaso de atribuciones respecto del tema ambiental, la pavimentación de calles y regulación de tránsito, temas tradicionales de conflicto con otras autoridades. Además, señaló: "no es posible que nos pidan preocuparnos de los problemas de la mujer, los niños, los jóvenes, la drogadicción y el medio ambiente si no se nos proveen los recursos para ello". Por esto "uno de los objetivos de la nueva agrupación debe(ía) ser la lucha por la modificación a la Ley de Municipalidades, así como asistir a la discusión en torno a la ley del Estatuto de los funcionarios de la salud y a la Ley de Plantas Municipales"19. De esta forma se trazaba el destino del naciente gremio, la demanda por recursos, democracia y atribuciones se convertiría en su tridente que dirigiría el norte de la agrupación. Así las cosas, 1300 delegados con más de 315 alcaldes de todo Chile se dieron cita durante los tres días del congreso inaugural entre la ciudad puerto y Viña del Mar. La tónica general fue la constante queja de los diversos ediles por la falta de recursos para sus comunidades, generándose una suerte de catarsis colectiva y añoranzas para cumplir sus objetivos. ¿Cuál fue el origen de esta iniciativa y qué tan inédito era en la historia de Chile? Si bien en la prensa se reconocía que había existido una asociación de alcaldes previa al golpe, esta siempre estuvo supeditada a los partidos, no cumpliendo un papel relevante en el pasado. Por el contrario, ahora, tras las primeras elecciones de autoridades locales luego del retorno democrático ${ }^{20}$, la

${ }_{17}$ Edison Hurtado, Martín Paladino y Gabriel Vommaro, "Las dimensiones del trabajo político: destrezas, escalas, recursos y trayectorias. Presentación del dossier", Iconos FLACSO-Ecuador 60, 2018, 11-29.

18 El Mercurio de Valparaíso, del 8 de mayo de 1993. Cuerpo A, p.5.

19 El Mercurio de Valparaíso, del 10 de mayo de 1993. Cuerpo A, pp. 1, 8.

${ }^{20}$ En el marco de la política de los consensos, estas elecciones implicaron que los ciudadanos votaran por concejales y en caso de que nadie alcanzara el 35\% de las preferencias para ser electo directamente como alcalde, los concejales electos designarían a los ediles según los acuerdos de los propios conglomerados. Para ello ver: Rolando Álvarez, "La reforma municipal en la transición: ¿Un caso de democratización en la medida de lo posible?”, Historial política.com, Buenos Aires, 2012, Disponible en: <http://historiapolitica.com/datos/biblioteca/chile_alvarezvallejo.pdf> 
iniciativa había nacido pensando en la autonomía de los municipios. Ravinet reconocía que la idea había surgido desde los ediles dados sus problemas comunes, así como también gracias a la asesoría de la Fundación Federich Erbert cuyo asesor principal y coordinador general era el joven geógrafo Giorgio Martelli quien se constituiría en su secretario ejecutivo. El objetivo era hacer una organización que representara los intereses del municipalismo desde una perspectiva despolitizada con un carácter gremial, un canal de solución de los problemas comunes ${ }^{21}$. Sin duda, quien representó de mejor manera el norte que tomaría la asociación fue la alcaldesa de Huechuraba Sofía Prats, quien sostuvo que la idea era: "constituir un interlocutor válido frente al poder Ejecutivo y Legislativo (...) cosa que ya comenzó cuando se formó la comisión organizadora el 28 de noviembre pasado (...) se piensa en una reforma municipal (dado que la anterior se hizo a la rápida) que permita la elección directa de los alcaldes, donde parece haber consenso en los partidos"22.

Ahora bien, todo parto implica dolores y las tensiones se desarrollaron al calor de los representantes locales que no estaban en la línea gruesa del oficialismo. En su mayoría, representantes del PC y el MIDA reclamaron la escasa representación que habían logrado, así como también la inexistencia de un proceso democrático en la elección para la presidencia de la ACHM, puesto que a su juicio todo habría venido "amarrado" desde Santiago con la Democracia Cristiana como cabecilla. Su rechazo lo manifestaron con incidentes a través de silbatinas generalizadas que la prensa registró y consultó a Jaime Ravinet. Al respecto, este sostuvo que simplemente eran un berrinche (sic) del Partido Comunista quien no podría integrar la mesa nacional porque contaba con apenas un $1 \%$ de los concejales. "Para ello tendríamos que organizar un directorio con cien integrantes", sostuvo 23 . Evidentemente la queja algo de cierto tenía, pues efectivamente no hubo elección, sino que la ratificación de la mesa (negociada previamente) se dio por aclamación popular. A pesar de esto, la agrupación quedaba en pie y dispuesta a luchar. Contaría con recursos frescos $(0,2 \%$ de los presupuestos municipales), una estructura subdividida en capítulos regionales y provinciales, además de sesiones programadas con diversas comisiones de trabajo, capacitaciones, y hasta descuentos con empresas de servicios hoteleros. Manifestando un fuerte sentido corporativo ${ }^{24}$.

Una de las primeras coyunturas relevantes para el naciente gremio fue la Ley de Plantas Municipales. Esta legislación se demandaba con urgencia, puesto que se requería de personal idóneo para cumplir las necesidades que implicaba la gestión municipal. Como mecanismo momentáneo se había aplicado la figura de contratas, lo que impedía el ingreso de los trabajadores a la carrera funcionaria, además de generar renovación anual sin contar con años de indemnización en caso del cese de actividades. A ello se le agregó otro grupo importante de trabajadores bajo la figura de honorarios, todo muy a fin a la flexibilidad neoliberal. De hecho, según informes oficiales solicitados durante la discusión parlamentaria, para diciembre de 1992 el número de personal municipal ya sobrepasaba los veinticinco mil trabajadores. ${ }^{25}$ Aunque Pinochet antes de dejar el poder envió un decreto que incorporaba a la carrera funcionaria al personal ingresado desde 1981, la Contraloría General de la República no tomó razón de ello y, por tanto, desde aquella fecha que no se habrían incorporado trabajadores a la planta municipal a pesar de la gran cantidad de nuevas funciones y atribuciones que envolvió la reforma municipal del régimen. De esta forma, los alcaldes desplegaron una estrategia amplia para acelerar la tramitación de la ley, lo que implicó: lobby intra-partidario, uso de los medios de comunicación, creación de una comisión propia dentro de su agrupación, una alianza con la asociación de funcionarios municipales y la asistencia a los debates parlamentarios, repletando las graderías del congreso, todo esto para generar presión a su

\footnotetext{
${ }_{21}$ Memorias 95-96 ACHM, p. 9; La Nación, 3 de mayo de 1993, p.6.

22 La Nación, 7 de mayo de 1993, p.5.

${ }^{23}$ La Nación, 9 de mayo de 1993, p.6

24 Memorias 95-96 ACHM, pp. 21-28.

${ }^{25}$ Historia de la Ley n 19.280, 21 de abril de 1993, p.7.
} 
demanda. De hecho, tanto los senadores Rafael Otero (RN) como Gabriel Valdés (PDC) se quejaron en innumerables ocasiones sobre la presión que ejercía la asociación de alcaldes, sumado a la gente que pifiaba desde el público cuando los debates no iban en la línea que se esperaba. ${ }^{26}$ Ejemplo de esto fue la situación que aconteció cuando en una sesión nocturna de la cámara de diputados por falta de quórum el debate no se pudo desarrollar, postergando entonces la discusión de la ley. Ante tan situación, tanto el alcalde Hernán Pinto como Jaime Ravinet, persiguieron por los pasillos del parlamento al presidente de la corporación Jorge Molina (PPD), llegando a increparlo en su oficina y amenazar con sumar a un paro convocado para el otro día por parte de la agrupación de funcionarios municipales ${ }^{27}$. Es que el escenario no era el mejor para el gobierno de Aylwin, pues venían saliendo de un importante paro de trabajadores de la salud (el primero de la transición) donde terminaron negociando con aquel gremio. 28 Pero además se aproximaban las elecciones parlamentarias y presidenciales, lo que hacía necesario contar con el apoyo de los alcaldes. A Boeninguer le urgía, pues, terminar el gobierno con un cierre transicional en paz social. Bajo este escenario el proceso legislativo tendió a acelerarse y la estrategia de los ediles se mantuvo en pie con los funcionarios en las graderías cada vez más vigilantes. Hubo de igual forma algunos parlamentarios que simpatizaron con el escenario y se sumaron a la demanda de los ediles, como el caso del diputado Mario Palestro (PS) quien, argumentando su voto a favor de la ley increpó a un colega sosteniendo que, en vez de quienes buscaban retrasar el proyecto, él nunca había perdido el norte de la defensa de los trabajadores, "no como el diputado señor Seguel (quien) ha sido un permanente demagogo, y de esos demagogos baratos, de a tres por docena" 29 . Finalmente, el proyecto vio la luz el 16 de noviembre del mismo año e implicó la incorporación a planta de los funcionarios. Para esto, cada alcalde debía hacer una consulta al concejo y a la asociación de trabajadores de gobiernos locales más antigua, así como aumentar a un tope del 10\% del presupuesto para funcionarios a honorarios, junto a un bono de $\$ 60.000$ para los trabajadores en paro. De igual forma las relaciones quedaron tensas, pues el senador Ricardo Hormazábal instó al presidente de la ACHM Jaime Ravinet a referirse con más recato a las autoridades del Estado ${ }^{30}$. Con todo, la estrategia amplia de los alcaldes y el respaldo de su asociación brindaron el apoyo necesario para conseguir el primero de sus objetivos y, lejos de conformarse, fueron por más. A nuestro juicio, esta primera coyuntura era indicativa del perfil que tomaría la agrupación y el desarrollo del municipalismo. Un colectivo con marcado tinte gremial, fue liderado por ediles que eran figuras locales empoderadas que, colaboraban en una plataforma para unir fuerzas en torno a las demandas municipales. Gran parte de ellos, sino todos, con una conflictiva autonomía hacia sus partidos, desplegaron una estrategia que incorporó tanto el debate como su colaboración modificando la subordinación vertical de antaño.

Dentro de su horizonte próximo se encontraba la necesidad de abastecerse con más recursos y para eso la Ley de Rentas Municipales jugaría un rol crucial. En mayo de 1994 fue el momento de dar la lucha para sanear los déficits presupuestarios que arrastraban los gobiernos locales, sobre todo en las áreas de educación y salud. A grandes rasgos, la propuesta del gobierno de Eduardo Frei Ruiz-Tagle contenía un aumento de la recaudación municipal que ascendería a $\$ 30$ mil millones; ello por la vía del incremento en un $10 \%$ de los permisos de circulación y las contribuciones de bienes raíces, además de

${ }^{26}$ Historia de la Ley $n^{0} 19.280,3$ de noviembre de 1993, p.26.

27 El Mercurio de Valparaíso, 4 de noviembre de 1993 Cuerpo B, p.2.

${ }_{28}$ El Siglo, 7 de octubre de 1993, p.3

${ }^{29}$ Historia de la Ley $n^{\circ} 19.280,9$ de noviembre de 1993, p.13. La gran capacidad de gestión y acción colectiva que ha tenido la asociación sobre el tema de la descentralización ha sido analizada por Mardones, para ello ver: Rodrigo, Mardones, "Descentralización y transición en chile", Revista de Ciencia política, 26, 1, Santiago, 2006. [citado 2018-11-01], pp.03-24. Disponible en:

$<$ https://scielo.conicyt.cl/scielo.php?script=sci_arttext\&pid=S0718-090X2006000100001\&lng=es\&nrm=iso $>$. ISSN 0718090X. http://dx.doi.org/10.4067/S0718-090X2006000100001.

30 Ibid., 16 de noviembre de 1993, p.4. 
un alza del $400 \%$ para las patentes comerciales y de un 100\% en las patentes comerciales temporales ${ }^{31}$. Al contrario de la ley de plantas, las posiciones ideológicas en este caso fueron mucho más claras. Desde ya, los grupos detractores de la ley fueron encabezados por los senadores Sebastián Piñera (RN), Francisco Javier Errázuriz (UCC) a quienes se sumaron los empresarios agrupados en la SOFOFA. Todos ellos argumentaron que la propuesta era un alza de impuestos camu flada. La reacción del gobierno estuvo a cargo del Subsecretario de Desarrollo Regional Jorge Rodríguez Grossi, quien acusó a los opositores de negarse al proyecto por los intereses creados que tendrían con sus propias empresas (LAN-Chile en el caso de Piñera y Unimarc en el caso de Errázuriz) ${ }^{32}$. Ante tales declaraciones la indignación cundió en el ambiente, la derecha pidió sacar a los "ministros socialistas" y encaró el origen extranjero (Italia) de los fondos de las campañas de partidos de gobierno, mientras que parlamentarios oficialistas respondieron llamando a la derecha a responder por los detenidos desaparecidos "antes de dar lecciones de moral". Además, agregaron que era sabido que el financiamiento empresarial de las campañas de sus adversarios era un mecanismo para defender sus intereses en el parlamento, según lo había declarado el propio Juan Carlos Délano presidente de la Cámara del Comercio. ${ }^{33}$ Con este tono de debate, tiempo más tarde Renovación Nacional interpondría una querella contra el Subsecretario Rodríguez Grossi ${ }^{34}$.

¿Qué rol jugaron los alcaldes en esta coyuntura? De manera unida defendieron la propuesta del gobierno y aumentaron la presión a la agenda mediante su repertorio ya probado, incorporando esta vez una nueva amenaza: en caso de no lograr un acuerdo para aprobar prontamente la Ley de Rentas, devolverían a nivel central tanto los consultorios como los colegios, entidades que a su juicio demandaban mayores recursos ${ }^{35}$. Llegado a este punto, el consenso fue necesario y durante los mismos días se comenzó a fraguar un acuerdo entre Andrés Allamand, los ministros Germán Correa y Eduardo Aninat y el senador Andrés Zaldívar. Dicho acuerdo implicaba recaudar menos de lo presupuestado, puesto que, aunque mantendría la idea del aumento del pago de patentes comerciales e industriales, no se habría aprobado el alza del 10\% en los permisos de circulación. A cambio, quedaba instalada una indicación de Ominami, para que las comunas de Vitacura, Las Condes y Providencia aportaran un 10\% más al Fondo Común Municipal ${ }^{36}$. Aunque un par de meses después el presidente de la SOFOFA anunció que se estaba organizando junto a doce parlamentarios una denuncia en el Tribunal Constitucional para impugnar el proyecto, la ley fue finalmente promulgada en mayo de $1995^{37}$. Con esto los ediles agrupados en su gremio avanzaban en sus demandas y salían fortalecidos en su organización. Aunque a su juicio los recursos no eran aún suficientes para satisfacer las necesidades, de igual forma era un logro, pues habían consolidado su referente como portavoz de las demandas municipales.

En paralelo a las coyunturas anteriormente descritas se aprobaron dos leyes de juntas de vecinos. La primera, $\mathrm{n}^{\circ} 19.418$, se encontraba en proceso legislativo desde 1990 y tras serias impugnaciones por la cantidad de juntas que podrían existir por unidad vecinal se dio aprobada recién en 1995 incorporando dos elementos relevantes: a) la existencia libre de cantidad de asociaciones de vecinos por territorio y la creación de los Fondos de Desarrollo Vecinal (FONDEVE) como un mecanismo más impersonal (vía concurso) que permitiera la asignación de fondos para las distintas necesidades del vecindario. Sin embargo, tras un año de su aprobación y en vista de la declarada mala calidad de la misma (contradicciones jurídicas e incluso referencia a registros que no existían) el gobierno de Frei mediante un rápido trámite de siete meses, aprobó una segunda ley vecinal ( $\mathrm{n}^{\circ}$ 19.483), la que en cuanto al primer elemento instaló

\footnotetext{
31 La Nación, del 3 de mayo de 1994, p.14.

32 Ibid., 5 de agosto de 1994, pp. 1, 5.

33 Idem, 5 de agosto de 1994, pp. 1, 5-6.

${ }^{34}$ La Nación, del 10 de agosto de 1994, pp. 1, 2-4.

35 Ibid., 16 de agosto de 1994, p.30.

36 Ibid., 19 de agosto de 1994, p.6.

${ }^{37}$ Ibid., 20 de mayo de 1995, p.13.
} 
un piso mínimo y exiguo de personas para el nacimiento de una agrupación en relación con el total de población de la comuna; mientras, sobre lo segundo, mantuvo la dinámica del FONDEVE tal cual se regía en la primera ley. ¿Qué implicancias tuvo esto para los alcaldes? En términos generales, la entrega de fondos mediante la competencia por concursos era un principio que de manera autónoma venía funcionando en los gobiernos locales, ya fuera con fondos propios o recibidos a través de la SUBDERE como parte de la focalización de política social, tal y como había sido pensado con la reforma municipal de la dictadura militar. Sin embargo, ambas leyes de juntas de vecinos, no reglamentaron un elemento crucial para el tejido clientelar territorial, como lo era la prohibición de entregar fondos por fuera de este programa. Es decir, no quedó prohibido asignar subvenciones más allá de los propios fondos vecinales. Por tanto, los ediles siguieron distribuyendo fondos de manera selectiva como un mecanismo clásico en la operación clientelar, solidificando su fortaleza sobre el territorio. ${ }^{38}$ De esta forma, uno de los mecanismos que venían operando para la construcción de capital político por parte de los ediles no fue restringido, por el contrario se potenció. A su vez, esto repercutió en una manera de comprender la participación democrática de la ciudadanía en su vinculación con el gobierno local, toda vez que se asumía que la asignación de fondos de acuerdo al formato de proyectos territoriales era una efectiva forma de incorporación de la sociedad civil. En parte, esto implica efectivamente un mecanismo de interacción entre ciudadanía local y gobierno municipal, sin embargo, se desliga del aspecto más relevante de la participación, como es la deliberación en materias municipales. Con esto, la participación y vinculación de los vecinos con el alcalde, mostraba fuertes continuidades con el periodo dictatorial

Ahora, esta última etapa de demandas municipales se cerró con la reforma a la Ley Orgánica de Municipalidades. Para esto los ediles se fueron preparando con tiempo, y tal como consta en sus propios documentos, desarrollaron lo mejor de su repertorio colectivo para conseguir sus objetivos, lo que implicó la creación de comisiones internas para desplegar lobby tanto con los parlamentarios como con el Ejecutivo, asociaciones gremiales, partidos políticos, además de visitas del propio Subsecretario de Desarrollo Regional Marcelo Schilling a dependencias de la ACHM, así como intervenciones por la prensa $^{39}$. Dada la complejidad de la ley y la reticencia que provocaba en algunos actores políticos las modificaciones sobre el sistema electoral, la discusión se fue aplazando. Por su parte, la asociación defendía consolidar el rol ejecutivo y administrador del alcalde, además de la función normativa, resolutiva y fiscalizadora del concejo. A esto agregaban la necesidad de mayor flexibilidad, autonomía y financiamiento estatal. Con respecto a los mecanismos de elección su posición era clara: debían ser separadas ${ }^{40}$. Tras el estancamiento del debate, los alcaldes solicitaron la división de la discusión en dos grandes temas: lo electoral y lo relacionado a funciones. Su demanda fue escuchada y así se hizo ${ }^{41}$. Luego de una larga y tensa discusión en septiembre, diputados de Renovación Nacional se aliaron al acuerdo de parlamentarios oficialistas, aislando con esto al sector gremialista, y aprobaron un nuevo mecanismo electoral para los alcaldes. Este implicaba que el sillón edilicio quedaría en manos de quien obtuviera la primera mayoría comunal de la lista que tuviere el 30\% de los votos. En caso de que no se lograse dicho porcentaje, el puesto sería para la primera mayoría comunal siempre que su lista hubiera sido la ganadora. Finalmente, si no se cumplian los anteriores, correspondería al candidato más votado de la lista más $\operatorname{votada}^{42}$. Esto tuvo como consecuencia una derrota de la postura de la ACHM, la que, representada por Ravinet, criticó la resolución calificándola de: "un arreglín a espaldas de la ciudadanía. La gente y la asociación pidió elecciones separadas porque las personas quieren diferenciar funciones... esto demuestra que las directivas de los distintos partidos trabajan a espaldas de lo que la gente quiere." $43 \mathrm{La}$

\footnotetext{
38 Estudios recientes demuestran cómo, inclusive dentro de los propios FONDEVES se construye toda una ritualidad clientelar, para ello ver: Luján y Pérez, 153-163.

39 Memorias 95-96 ACHM, pp. 55-62.

40 El Mercurio de Valparaíso, 14 de marzo de 1995. Cuerpo A, pp. 1, 10.

${ }^{41}$ La Nación, del 27 de junio de 1995, p.13.

42 Ibid., 14 de septiembre de 1995, p.2.

43 Ibid., 14 de septiembre de 1995, p.3.
}

\section{(2) (2)}


respuesta del Subsecretario Schilling fue un llamado a la tranquilidad, pues a su juicio "lo mejor es (era) enemigo de lo bueno." 44 Es que efectivamente era un avance, puesto que para las elecciones de octubre de 1996 los ciudadanos podrían votar de manera directa por sus alcaldes aunque no separados tal y como había querido la Asociación. Sin embargo, la declaración de Ravinet criticando duramente a los partidos muestra también las tensiones propias de esta relación, donde, la actividad gremial, junto a la militancia política, convivieron conflictivamente. La fisura del viejo sistema de intermediación se iba consolidando en las particularidades de la transición. Aunque en este caso los partidos aún lograban imponerse sobre las demandas municipales, los costos asociados serían la acumulación de experiencia signada por la deuda desde los ediles y una paulatina fragmentación de los actores, por ello las redes articuladas en multi-escala (municipio-parlamento) fueron deviniendo en actores que acumulaban para si su propio capital político.

Por otro parte, ¿qué ocurrió con los elementos relacionados con la estructura, funciones y sentido del proyecto? Su discusión se prolongó por un año y medio más, siendo aprobada en octubre de 1997, tras el contexto de conmemoraciones del último año del general Pinochet al mando del ejército, quien preparaba su aterrizaje en el Parlamento. En este caso, los alcaldes a través de la ACHM comenzaron a hacer gestiones, amenazando públicamente con la devolución de consultorios y colegios al Estado.45 Reclamando más financiamiento y atribuciones, algunos de ellos inclusive lograron no renovar la "concesión de los consultorios", mientras que otros aumentaban su presión y lobby para obtener la segunda parte de su reforma. Ante la mirada atónita del gobierno, que temía una devolución más generalizada de las entidades de servicios, lograron empujar la aprobación de la ley, la que les otorgó atribuciones para pavimentar calles (por tanto, recursos que vendrían del nivel central), flexibilizar la planta municipal, crear corporaciones sin fines de lucro y ampliar las temáticas de plebiscitos para los gobiernos locales ${ }^{46}$. Con esto se cerraba una primera temporalidad de los ediles, donde, a nuestro juicio, su mayor logro fue el de avanzar en sus objetivos consolidando un repertorio de acción amplio, con una estrategia dual que incorporó a los partidos, pero perfiló una entidad más gremial, solidificando su asociación como el portavoz oficial del municipalismo. Ahora, los partidos políticos ya no eran exclusivamente los intermediarios de las demandas municipales. De hecho, fuentes de la propia asociación mostraban que para 1997 el gremio tenía más de veinte comisiones de trabajo permanente lideradas por alcaldes y concejales de diversos puntos del territorio nacional. Ellas proveían del análisis, debate y establecimiento de su propia agenda. Dentro de dichas comisiones se encontraban: internacional, finanzas, educación, seguridad ciudadana, salud, ley orgánica, control y desarrollo económico, entre otras. ${ }^{47}$ Además, se agregaban las comisiones creadas en el marco de coyunturas específicas que afectaran los intereses municipales como: reforma municipal, ley de rentas, reforma educacional y policía local, las que para la fecha alcanzaban cerca de catorce. ${ }^{48}$ Más aún, la propia organización ofrecía una serie de beneficios al más estilo orgánico mutual; ellas incorporaban seguros de vida y de accidentes personales tanto para alcaldes y concejales miembros del organismo, así como también tarifas rebajadas en hoteles de Santiago para los mismos, más funcionarios municipales integrantes del gremio. ${ }^{49}$ Por esto, cerrando esta primera temporalidad, la ACHM sostenía que habían logrado finalizar la etapa de consolidación, pues poseían la representación del $99 \%$ de los municipios convirtiéndose "sin lugar a duda en un referente y una portavoz representativa, considerada y respetada de los Gobiernos Locales de nuestro país" 50 . A juicio de sus dirigentes, la clave de este éxito había pasado por el hecho de lograr posponer "las posiciones

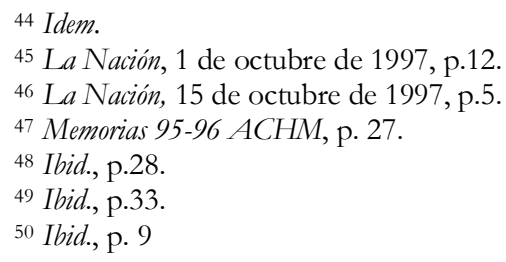


político partidistas para dar paso a una posición claramente municipalista". ${ }^{51}$ Finalmente, desde el punto de vista del modelo municipal y la democracia, las demandas de la Asociación se redujeron en torno a las formas de elección (directas y separadas) generando un vació en torno a la participación y deliberación de los diversos actores en torno al gobierno local, es decir las líneas de continuidad en el contexto transicional fueron más fuertes, co-ayudando con esto al proceso de erosión del viejo sistema de intermediación local-nacional.

\section{3.- Segunda temporalidad: 1998-2005.}

Para la segunda fase del desarrollo gremial, los alcaldes mantuvieron su repertorio de acción, el que como hemos visto, implicó los más variados recursos: desde lobby intra-partidario, hasta movilización de masas, utilización de medios de comunicación y mecanismos de presión como la amenaza de la devolución de consultorios y establecimientos educacionales. Su horizonte político-gremial se mantuvo en un tridente ofensivo que contempló: mayores atribuciones, más recursos y elementos electorales; es decir, poder, dinero y democracia. Sin embargo, la transición chilena fue mostrando cambios no menores en su desarrollo, Pinochet luego de su llegada al Parlamento era detenido en Londres en 199852, así como también la UDI iba dando muestras de su avance electoral y la figura de Lavín comenzaba a despuntar como un candidato presidencial de la derecha. Ello repercutió tanto en la interna del gremio, como en la escena pública. Ante ello, los ediles se fueron adaptando a su propio contexto.

Durante 1999 lograron una reforma municipal que había sido separada por razones políticas de sus aspectos electorales, ello fomentó medidas de protección para seguridad ciudadana, gestión y desarrollo, así como la generación obligatoria de Planes de Desarrollo Comunal (PLADECOS) y la elaboración del Plan Regulador. Además, se aumentaba la remuneración a los concejales junto a exigir al alcalde informar por escrito al concejo municipal por licitaciones públicas y propuestas privadas ${ }^{53}$.

$\mathrm{Al}$ año siguiente, bajo el gobierno de Lagos, se enfrentaron a la disminución de los planes de empleo, los que, como medida paliativa de los efectos de la crisis asiática, llevó a encender las alarmas de los ediles, enfrentándose en distintas ocasiones a manifestaciones en las afuera de los edificios municipales por parte de los cesantes quienes reclamaban por el cese de sus funciones ${ }^{54}$. La respuesta del gobierno mediante el Subsecretario Vidal fue seca: los planes duraban hasta diciembre, pero contando las personas que habían sido contratadas hasta diciembre del año anterior ${ }^{55}$. ¿Cómo respondió la ACHM ante tajante postura? Los ediles pusieron todo su repertorio acostumbrado sobre la mesa. Dentro de ello se exigió una reunión con el propio presidente, quien se vio en la obligación de recibirlos, al mismo tiempo que aumentaron su presión por los medios. En este escenario, la opinión pública hacia ver al gobierno como el responsable de dejar a personas sin trabajo en medio de la crisis, por tanto, tuvo que ceder declarando que no dejarían cesante a ningún ciudadano. Sin embargo, exigían a los alcaldes que no siguieran contratando gente en lo que restaba del año ${ }^{56}$. Más tarde, el propio Ministro de Hacienda, Nicolás Eyzaguirre aseguraba que de los cerca de 50 mil trabajadores contratados por los Planes Generales de Empleo (PEM) serían reubicados en programas administrados por otros organismos del gobierno (FOSIS, SENCE y MOP). Para cerca del 60\% restante, el gobierno se comprometía a traspasar fondos por diez mil millones de pesos, con el objeto de mantener los programas al menos durante los tres próximos meses. ${ }^{57} \mathrm{~A}$ nuestro juicio, este es un ejemplo más de las fisuras que se iban produciendo en el

\footnotetext{
51 Idem.

52 Ercilla, no 3.097, del 2-15 de noviembre de 1998.

53 El Mercurio de Valparaíso, 13 de marzo de 1999. Cuerpo B, p.1.

${ }^{54}$ La Nación, d3 de abril de 2000, L y N, p.3.

55 Ibid.

56 El Mercurio de Valparaíso, 5 de abril de 2000. Cuerpo A, p.10.

${ }^{57}$ La Nación, 29 de julio de 2000, p.4.
} 
viejo sistema de intermediación local-nacional articulado en el pasado hegemónicamente en los partidos políticos, los cuales se vieron incapacitados de "bajar" esta demanda.

Ahora bien, ¿qué elementos de la macro-política transicional repercutieron en el desarrollo histórico de los ediles y de qué manera ellos decantaron en el gremio de alcaldes? Para las elecciones municipales del año 2000 la figura descollante de la derecha -Joaquín Lavín- logró derrotar a la Concertación en la comuna más importante de Chile, Santiago. Ello implicó un desafío para el lavinismo (se trataba de administrar una comuna diferente de Las Condes, más heterogénea desde el punto de vista socio-económico) y por tanto pondría a prueba su estilo compitiendo - en cierta medida- con la gestión en el Ejecutivo de Ricardo Lagos, su ex contendor en las elecciones del año anterior ${ }^{58}$. Además, la figura edilicia de la derecha fue un ejemplo fiel de cómo era posible saltar de un sillón local a una carrera presidencial y estar a punto de ganarle a un líder histórico de la centro-izquierda. Tal como se señaló en la prensa de la época, el municipio había dejado de ser el pariente pobre de la política chilena ${ }^{59}$.

En este sentido, el avance de la derecha a nivel político repercutió en las elecciones internas de la ACHM, donde por primera vez para el año 2001 la Concertación se vio en la obligación de compartir la presidencia del gremio. Estableciendo un acuerdo con la derecha, se implantó la idea de que la democracia-cristiana ocuparía la testera por los primeros dos años, para luego dar paso a la derecha. En la centro-izquierda el poderoso cacique porteño Hernán Pinto -quien contaba con una maquinaria clientelar que le permitió mantenerse en el piso de los 58 mil votos por doce años-, logró imponerse en la interna de la DC asegurando su futuro liderazgo en la gremial. Como contra partida, la derecha impuso a Manuel José Ossandón para los próximos dos años. De esta forma, la Asociación Chilena de Municipalidades por primera vez en su historia sería gobernada por la derecha, resignándose la Concertación a un nuevo escenario político. Así las cosas, mientras que el flamante presidente Hernán Pinto declaraba agotado el modelo municipal vigente y llamaba a luchar por más atribuciones y recursos ${ }^{60}$, el ahora bi-ministro Ravinet declaraba a sus ex-correligionarios a estar felices, pues recientemente se había aprobado la elección separada de alcaldes y concejales, representando un triunfo para la democratización de los gobiernos locales ${ }^{61}$. Ante este nuevo escenario ¿qué ocurrió con las demandas por recursos?, ¿fue la derecha un actor que amainó las implicancias que traería una nueva alza de contribuciones o más bien mantuvo un perfil netamente gremial?

Durante este segundo tiempo transicional, el problema de los recursos transitó en distintas etapas. La primera de ellas se inició a fines del gobierno de Frei Ruiz-Tagle, pero su tramitación dura se desarrolló durante el inicio del periodo de Lagos con Francisco Vidal a la cabeza como Subsecretario de Desarrollo Regional. Esto implicó una reforma a la denominada Ley de Rentas I. En la postura de Vidal, el proyecto permitía aumentar del 50\% al 75\% el aporte que hacían los municipios al Fondo Común Municipal (FCM) por concepto de permisos de circulación, además de subir de cuatro a ocho unidades tributarias mensuales (UTM) por pago de patentes comerciales y elevar del 60 al 65\% el aporte de las cuatro comunas más ricas al FCM de lo que recaudaban en contribuciones. Esto representaba una inyección de recursos frescos a las comunas más pobres de $\$ 20.000$ millones de pesos, sin afectar el presupuesto de las comunidades que más aportaban ${ }^{62}$. La postura de la asociación fue de respaldar plenamente al gobierno, puesto que aún la derecha no terminaba de instalarse cómodamente al interior del gremio. Aunque las críticas de los empresarios se hicieron ver, el debate tendió a concentrarse en la negociación parlamentaria, en la que el impulso inicial fue amainando dados los acuerdos necesarios para su aprobación. De esta forma el consenso con la oposición salvó el proyecto que implicó subir sólo al

58 Valdivia, Verónica, "La derecha pinochetista en el post-pinochetismo: auge y crisis del lavinismo 2000-2004”, Revista Estudos Ibero-Americanos, 42, 2, Rio Grande do Sul, 2016, 694-723.

${ }^{59}$ Ercilla $\mathrm{n}^{\circ} 3.164,15-28$ mayo, 2000.

${ }^{60}$ Memorias ACHM 2001-2003, p.67.

${ }^{61}$ La Nación, 10 de mayo de 2001, p.8.

${ }^{62}$ El Mercurio de Valparaíso, 15 de julio de 2000. Cuerpo B, p.1. 
62,5\% los aportes al FCM por concepto de permisos de circulación. Sin embargo, el aumento de 4 mil a 8 mil UTM como tope para el pago de patentes comerciales logró ser aprobada junto al alza del $60 \%$ al $65 \%$ por concepto de impuesto territorial al FCM de Providencia, Las Condes, Santiago y Vitacura, lo que permitiría aumentar unos 20 mil millones de pesos $^{63}$. Ante esto el gobierno concluía señalando que dicha ley sintetizaba su norte: "crecer con igualdad", puesto que implicaba inyectar recursos y redistribuir. Sin embargo, como se podrá apreciar la estructura y el sentido del gobierno municipal instalado durante la dictadura, la participación efectiva a través de fuertes medidas de contrapeso a la figura del alcalde, no eran puestos en agenda. El edificio estaba bien; de lo que se trataba era distribuir mejor para focalizar, parecía ser la noción de fondo.

Por otra parte, la segunda etapa del problema de los fondos fue mucho más tensa, puesto que implicaba avanzar con mayor decisión en la obtención de recursos. Dado este carácter, el proyecto venidero fue bautizado por la prensa como Ley de Rentas II. Iniciado el año 2002 el Subsecretario Vidal presentó públicamente el proyecto declarando que el objetivo era acortar la brecha entre los municipios más pobres, incrementando el Fondo Común Municipal entre $\$ 300.000$ a $\$ 345.000$ millones anuales ${ }^{64}$. Las repercusiones a nivel de partidos se hicieron ver. Por una parte, Renovación Nacional encendió las alarmas y diversos senadores se opusieron acusando nuevamente de un alza de impuestos soterrada ${ }^{65}$. A su vez, la propia Democracia Cristiana generó un frente de oposición interna mediante la presidencia de Adolfo Zaldívar, quien se arrogaba la representación de la "clase media" y se articulaba con gremios empresariales para evitar una "avalancha tributaria". Es que las cosas con el partido de la flecha roja y el gobierno venían mal desde hacía tiempo, sobre todo después de la derrota electoral de la DC en las parlamentarias de 2001. En este escenario, la estrategia del Ejecutivo fue temeraria. Mediante su Ministro del Interior, José Miguel Insulza, se avocó a una negociación directa con la derecha representada en Pablo Longueria, quien como presidente del gremialismo, aseguraría el apoyo de su partido en bloque ${ }^{66}$. El gobierno de Lagos pretendía sacar del parlamento el debate mediante la denominada "comisión técnica", la que le permitiría llegar a acuerdos necesarios previo al debate en el Congreso y con eso asegurar una vía expedita para su aprobación. Sin embargo, Zaldívar reaccionó retirando a su partido de la mesa, dando una orden a sus parlamentarios de bloquear tal iniciativa, generando con ello una alianza con R.N. para evitar la llamada "avalancha tributaria" 67 . En este escenario, el gobierno optó por integrar al proyecto la mayoría de las indicaciones negociadas y apostó a que el peso de los medios de comunicación se dejase caer sobre quienes se opusieran al proyecto, puesto que sabido era por todos que al oponerse a la medida se estaría negando mayores recursos para políticas sociales.

Ante esta coyuntura ¿qué ocurrió en la ACHM? Las repercusiones a nivel gremial fueron fuertes. Desde ya, quien supondría que ocuparía el sillón del gremio, Manuel José Ossandón, tomo la delantera e intentó quebrar el organismo. Mediante una acusación a Pinto de defender exclusivamente al gobierno, hizo un llamado a formar una nueva organización "Alcaldes por Chile", la que tendría su propio congreso inaugural y presentaría un nuevo proyecto de rentas que no implicase un alza de impuestos ${ }^{68}$. Ante tal desafío, Pinto denunció el intento de politizar la asociación y llamó a la cordura, puesto que el apoyo al gobierno había sido votado en sesiones anteriores de la agrupación. Pero más aún, de manera estratégica logró contener la fuga de alcaldes negociando el apoyo de Pedro Sabat (RN), quien firmó como nuevo vicepresidente. Aclamado por unanimidad, el alcalde de derecha desbancaba la línea de Ossandón y llamaba al orden. Reconociendo la legítima autoridad y liderazgo de Pinto, Sabat señaló la necesidad de superar las divisiones sin sentido, puesto que "esto es (era) municipalidad y no politiquería". ${ }^{69}$ Con esto

\footnotetext{
${ }^{63}$ La Nación, 30 de noviembre de 2000, p.8.

${ }^{64}$ Ibid., 1 de marzo de 2002, L \& N, p.31.

${ }^{65}$ Ibid., 6 de marzo de 2002, p.6.

${ }^{66}$ La Nación, del 16 de mayo de 2002, p.2.

${ }^{67}$ Ibid., del 1 de agosto de 2002, p.2.

68 Ibid., del 26 de mayo de 2002, p.5.

${ }^{69}$ El Mercurio de Valparaíso, del 2 de julio de 2002. Cuerpo B, p.2.
} 
el choque de caudillos se resolvía a favor del cacique del puerto, aislando al edil de Puente Alto, quien de pasada perdería su cupo para la futura presidencia. El alcalde de Ñunoa se estaba probando la corona. Dos meses más tarde, Pinto demostraría su liderazgo y el uso de masas cuando citara en el Teatro Municipal de Valparaíso a una reunión de la ACHM con el objeto de presionar para la pronta aprobación del proyecto. En esta ocasión, como orador principal se dedicó a incendiar la asamblea, la que, siguiendo a su líder, salió marchando a una cuadra del Congreso, donde, cubiertos de prensa y escándalo, entregaron un petitorio a los parlamentarios para agilizar la tramitación del proyecto..$^{70} \mathrm{~A}$ pesar de esto, el proceso continuó su curso natural de debate parlamentario. En esto último, la Asociación articulada con representantes legislativos, mantuvo su estrategia de presión, llenando las graderías de alcaldes y sus equipos políticos. Por ejemplo, Camilo Escalona saludaba el apoyo de Johnny Carrasco de Pudahuel y Ramón Aguilera, así como Lorenzini imploraba la aprobación, puesto que serían los municipios los que gobernarían el país con la gente..$^{71} \mathrm{Al}$ año siguiente, y con Sabat a la cabeza del gremio, llegaron a su medida extrema: decretaron una huelga municipal. Con dispares resultados, en Santiago algunos alcaldes UDI como Zalaquet se restaron de tal evento, mientras que Valparaíso todo el capítulo regional se sumó, terminando con una movilización hacia la Intendencia liderada por Luis Guastavino. Días más tarde, los acuerdos en el Legislativo salieron a la luz. En ellos, las posturas de la DC sobre la exención impositiva a clubes deportivos primó, solo a condición de que la institución facilitara gratuitamente la infraestructura a una comunidad escolar municipal o particular subvencionada, así como también el re-avalúo automático de terrenos eriazos en proceso de "engorda", lo que implicaba incrementar los tributos para el gobierno local $^{72}$. Finalmente, el primero de julio del año 2005 y tras los agradecimientos de la Subsecretaria Adriana del Piano a los parlamentarios, la Ley n ${ }^{\circ} 20.033$, llamada Ley de Rentas II, era publicada. Con esto, los acaldes aseguraban un nuevo paso en su lucha por más recursos. Ahora esperaban recibir por la nueva reglamentación de rentas $\$ 56.000$ millones de pesos más, claro está, para poder mejorar sus servicios de focalización, cerrando con esto su propia transición. De esta forma, desde la asociación veían este último ciclo como de avances cuyo punto de inflexión habían sido las declaraciones de Mejillones, de Nuñoa "y luego la jornada de reflexión y protesta por la actitud indiferente y despreciativa del Ejecutivo y el Parlamento antes las justas demandas de alcaldes y concejales, en beneficio de los chilenos. Esa justa lucha dio sus frutos y rápidamente fueron acelerados o aprobados proyectos que, como señalaran los dirigentes de la ACHM descansaban el sueño de los justos en el Parlamento o el Ejecutivo". ${ }^{73}$ Su estrategia había dado frutos.

\section{Consideraciones finales}

A más de cuarenta años de la publicación de la tesis doctoral de Valenzuela, el nacimiento y desarrollo de la Asociación Chilena de Municipalidades muestra cambios y continuidades en las dinámicas locales. El favor y la construcción de clientelas locales siguieron siendo una pesada costumbre política dentro de la resurrección del sistema de partidos chileno tras el retorno democrático. Más aún cuando la propia reforma municipal privilegió el contacto con la ciudadanía a nivel local. Sin embargo, esta vez los alcaldes - base del viejo sistema-, terminaron agrupándose con un fuerte sentido de gremio desarrollando una estrategia dual para canalizar sus demandas. Su trabajo político consistió tanto en mantenerse en sus partidos, como desplegar todo un amplio repertorio a fin de instalar sus demandas dirigidas por el tridente recursos, atribuciones y democracia. La fortaleza de estos líderes radicó principalmente en que potenciaron su capacidad territorial mediante su vínculo con sus electores. Sin embargo, la alcaldización

70 La Nación, del 11 de septiembre de 2002, p. 4.

71 Historia de la ley $n^{\circ} 20.033$. del 12 de agosto de 2003, p.14.

72 Historia de la Ley 20.033. Tercer trámite constitucional, 17 de mayo, de 2005 p. 28.

73 Memorias de la Asociación Chilena de Municipalidades 2002-2005, Santiago, p.35. 
supuso también límites, pues los partidos siguieron teniendo el monopolio de la inscripción de candidatos, así como también el propio sistema electoral binominal tendió a concentrar los incentivos en la nominación de listas a partir de la estabilidad electoral, evitando con eso una fuga radical de líderes personalistas por fuera del sistema.

Por ello, los alcaldes que quisieron ascender en su carrera política tuvieron que trazar redes "hacia arriba" de sus partidos, como los casos de Lavín en el mundo presidencial, o de Jacqueline Van Rysselberghe en la arena partidaria y legislativa. Otros avanzaron en experiencias más autonomistas como Jorge Soria en Iquique, y finalmente algunos se mantuvieron en el terreno local, como Hernán Pinto en Valparaíso. Con todo, a nuestro juicio, la ACHM fue un elemento más que ayudó a ir erosionando el eje articulador del sistema de intermediación a través de los partidos políticos. El presente artículo evidencia que la historia del gremio es también la historia del uso y abuso de las viejas redes partidistas. Sin embargo, hubo también elementos contextuales que repercutieron en esta dinámica. Desde ya, el fin de la Guerra Fría, la hegemonía de las lógicas neoliberales en la aplicación de políticas sociales, junto a las trazas de continuidad dictatorial explican también el denominado proceso de alcaldización de la política y la emergencia de estos liderazgos. Los ediles, y al contrario de lo esperado por las políticas públicas que se iban diseñando, tendieron a ir personificando su vínculo social mediante un clientelismo atomizado y fragmentado de demandas locales, desdibujando la antigua proyección ideológica-partidista que suponía la incorporación de dichas demandas, como parte del procesamiento del viejo sistema de intermediación. Además, hay que agregar la inexistencia de un proyecto contra-hegemónico de gobierno local de parte de la centro-izquierda para sopesar la pesada herencia autoritaria.

El desarrollo histórico del "gremio de alcaldes" demuestra cómo los ediles dirigieron sus demandas por mayores recursos y atribuciones sin trastocar el proyecto original dictatorial en cuanto a su sentido ideológico. Si bien se avanzó en la democratización en tanto acceso a cargos -algo no menor, por cierto- el municipio siguió siendo el ejecutor de la focalización de la política social, llegando los propios ediles a reclamar más recursos por considerarse así mismos los mejores "focalizadores". Desde el punto de vista de este artículo, la denominada "fractura" del sistema pasó por una historia de demandas locales paradojalmente con, y a ratos contra, los partidos.

Una perspectiva historiográfica permite evidenciar el desarrollo paulatino de este fenómeno, el que lejos de tomar un carácter mecánico, supuso un juego de contradicciones entre los propios personajes de esta historia. Es decir, los ediles no pasaron bruscamente de un ejercicio totalmente político a otro gremial. Más bien mediante las coyunturas analizadas, podemos observar cómo a ratos desplegaron sus demandas corporativas incluyendo lobby con sus propios partidos, así también cuando esto no les resultó, se abalanzaron con estrategias más abiertas de movilización que cuestionaron a los mismos. El análisis de coyunturas junto a los problemas que sucedieron en esta historia muestra la complejidad del fenómeno permitiendo tomar distancia de miradas que visualizan el ejercicio de la mediación como una práctica siempre expedita y lineal. Desde nuestro punto de vista, ahondar en las sombras de la democracia, permite pesquisar esas prácticas que a veces se silencian restándole importancia de análisis. Para este artículo, los juegos de poder desarrollados tras bambalinas son igual de importantes que las declaraciones públicas, pues permiten acceder a la intimidad donde se revela el trabajo político y por tanto, muestra cómo se opera en la crudeza misma de los hechos, sobre todo en una cultura política tan silente como la chilena.

Por otro lado, el despliegue de la estrategia de los ediles con su tridente ofensivo fue ayudando y al mismo tiempo adaptándose a las modificaciones del viejo sistema de intermediación loca-nacional que describió Valenzuela. Tal como lo ha señalado Durtson, es posible ver en este nuevo ciclo histórico un sistema de mediadores en competencia con rasgos más autónomos contra la integración vertical de antaño. Eso permite explicar las tácticas a ratos "contradictorias" de los alcaldes, toda vez que según Sergio Toro se fue produciendo la figura de legisladores más de tipo autorreferenciales, quienes acumulaban su propio capital político haciendo más difícil el traspaso de votos de manera tan clara como antes. En este sentido, mediante su Asociación, los alcaldes a ratos amagaron mediaciones legislativas 
cuando no les eran funcionales. Eso explicaría - ente otras cosas- los discursos más distantes hacia los partidos que fueron una constante en el periodo, ya fuese en alcaldes "de base" y distinto cuño ideológico, así como de parte de los líderes del propio gremio.

De igual forma, pensamos que es posible abrir nuevas problematizaciones sobre estos fenómenos a fin de complejizar las preguntas en torno al centralismo chileno en la historia reciente. Además, desde otras ciencias sociales es pertinente analizar las posibles las capacidades que tengan los partidos para limitar la autonomía de liderazgos en el marco del nuevo sistema electoral.

Sin perjuicio de lo anterior, desde una perspectiva historiográfica se requiere analizar las costumbres políticas practicadas al alero del Estado. Descender la mirada hacia la medicación entre actores sociales y políticos permitiría humanizar una historia a ratos excesivamente arquetípica del pasado chileno. De la misma forma, una aproximación interdisciplinaria, que aporte desde la multidimensionalidad y la multi-escala podría mostrarnos como se desarrolló el trabajo político "desde abajo", es decir con la gente de "carne y hueso" en la porosa relación entre el mundo social y los partidos políticos.

\section{Bibliografía}

\section{Impresas}

Evelyn, Arriagada, "Neopopulismo y clientelismo en la derecha chilena. La inserción de la UDI en una comuna popular del Gran Santiago", Memoria para optar al título profesional de antropóloga en Universidad de Chile, Santiago, 2008.

Luis, Corvalán, Del anticapitalismo al neoliberalismo en Chile, Editorial Sudamericana, Santiago, 2003.

Tomás, Dosek, "La presencia y el éxito de los independientes en las elecciones municipales en Chile (1992-2012), en: Luna y Mardones, La Columna vertebral fracturada. Revisitando intermediarios políticos en Chile, RIL Editores, Santiago, 2017.

John Durtson, Daniel Duhart, Francisca Miranda, Evelyn Monzó, Comunidades campesinas, agencias públicas y clientelismos políticos en Chile, LOM Ediciones, Santiago, 2005.

Juan Pablo Luna y Rodrigo, Mardones, La columna vertebral fracturada, RIL Editores, Santiago, 2017.

Aníbal, Pérez, La UDI tras el telón. Agitación social, lavinismo y clientelismo, Editorial América en Movimiento, Valparaíso, 2016.

Pérez, "En el canto del Estado. Del clientelismo programático al clientelismo neoliberal”, en Transiciones. Perspectivas historiográficas sobre la postdictadura chilena, 1988-2018, José Ponce, Aníbal Pérez y Nicolás Acevedo compiladores, Editorial América en Movimiento, Valparaíso, 2018.

Kenneth, Roberts, "El neoliberalismo y la transformacio $\square$ n del populismo en Ame $\square$ rica latina. El caso peruano", en: Mackinnon, Mari $\square$ a y Petrone, Mario (Eds.), Populismo y Neopopulismo en Ame $\square$ rica Latina. El problema de la Cenicienta, EUDEBA, Buenos Aires, 1999. pp. 375 - 408.

Sergio, Toro, "El vínculo distrital de los parlamentarios: continuidad y cambio de la estructura de intermediación local en Chile", en: Luna y Mardones, La columna vertebral fracturada, RIL Editores, Santiago, 2017, pp. 177-200. 
Arturo, Valenzuela, Political brokers in Chile, Durham, N.C., Duke University Press, 1977

Verónica Valdivia, Rolando Álvarez y Karen Donoso, La alcaldización de la política, LOM Ediciones, Santiago, 2012.

Fuentes primarias (1992-2005)

Revista Ercilla.

Diarios:

La Tercera.

La Nación.

El Mercurio.

El Siglo.

El Mercurio de Valparaíso.

La Estrella de Valparaíso.

Sur de Concepción.

Crónica de Concepción.

Memorias de la Asociación Chilena de Municipalidades (1995-2007).

Historia de la Ley n 19.280.

Historia de la Ley $n^{\circ} 19.483$.

Historia de la ley $n^{\circ} 20.033$.

\section{Electrónicas}

Rolando Álvarez, “Clientelismo y mediación política: Los casos de los municipios de Renca y Huechuraba en tiempos de la 'UDI Popular"', Divergencia, 6, Valparaíso, 2016, 41-53.

Álvarez, "La reforma municipal en la transición: ¿Un caso de democratización en la medida de lo posible?", Historia política.com, Buenos Aires, 2012, Disponible en:

$<$ http://historiapolitica.com/datos/biblioteca/chile_alvarezvallejo.pdf>

Evelyn Arriagada, "UDI: ¿partido popular o partido populista? Consideraciones sobre el éxito electoral del Partido Unión Demócrata Independiente en los sectores populares", Colección Ideas, 6, 51, Santiago, 2005.

Arriagada, "Clientelismo político y participación local ", Polis, 36, Santiago 2013, disponible en: http://journals.openedition.org/polis/9389.

Emmanuelle, Barozet, "La compra de los votos en Chile o cómo se coopta a los sectores populares", Contribuciones científicas y tecnológicas, 33,133, Santiago, 2000, 10-13.

Barozet, "Movilizacio $\square$ n de recursos y redes sociales en los neopopulismos: hipo $\square$ tesis de trabajo para el caso chileno", Revista de Ciencia Pol $\square$ tica, 23, 001, Santiago, 2003, 39-54.

Barozet, "Elementos explicativos de la votacio $\square$ n de los sectores populares en Iquique: lo $\square$ gica y eficiencia de las redes clientelares", Poli tica, 043, 2004, Santiago, 205-251. 
Barozet, "Populismo regional y Estado: el caso de Chile", Estudios Interdisciplinarios de América Latina y el Caribe 19 (2), Tel Aviv, 2007, 45-60, disponible en: http://repositorio.uchile.cl/handle/2250/121534.

Daniel, Cravacuore, "Los municipios argentinos (1990 - 2005)", en: Cravacuore e Israel, R. (comp.) Procesos políticos municipales comparados en Argentina y Chile (1990 - 2005), Editorial de la Universidad Nacional de Quilmes - Universidad Autónoma de Chile, Buenos Aires, 2007. Disponible en: http://www.econ.unicen.edu.ar/extension/vinculacion/images/Filminas/Los $\% 20$ municipios $\% 20$ argen tinos $\% 201990-2005 \% 20-\% 20$ Cravacuore $\% 202007$.pdf

Turid, Hagene, "Political Clientelism in Mexico: Bridging the Gap between Citizens and the State", Latin American Politics and Society, 57, 1, 2015, pp. 139-162. doi:10.1111/j.1548-2456.2015.00259.x,

Horacio, Cao, "La administracio $\square$ n pu $\square$ blica argentina: nacio $\square$ n, provincias y municipios", XIII Congreso Internacional del CLAD sobre la Reforma del Estado y de la Administracio $\square$ n Pu $\square$ blica, Buenos Aires, 2008, disponible en: https://www.horaciocao.com.ar/wp-content/uploads/2015/06/40-la-administracion.pdf

Vicente Espinoza y Sebastián Madrid, Trayectoria y eficacia política de los militantes en juventudes políticas. Estudio de la elite política emergente, Santiago, CEP, Proyectamerica, LYD, CIEPLAN, IDEA, USACH, Santiago, 2010.

Espinoza, "Los nuevos Agentes Políticos Locales: Revisión Estructural de la Tesis de Arturo Valenzuela ¿Cómo se articulan el nivel de representación local con el nacional en la arena local y qué papel juegan el gobierno central y las políticas públicas?” Revista Mad.,14, Departamento de Antropología, Universidad de Chile, Santiago, 2006, disponible en: http://www.revistamad.uchile.cl/14/espinoza.pdf.

David, Lujan, "Entre la autonomía y la dependencia. Lobby, clientelismo político e idea de estado en los contextos locales chilenos", Polis, 16, 48, Santiago, 2017, 133-154.

Edison Hurtado, Martín Paladino y Gabriel Vommaro, "Las dimensiones del trabajo político: destrezas, escalas, recursos y trayectorias. Presentación del dossier", Iconos Flacso-Ecuador 60, 2018, 11-29.

Luján y Pérez, "La Democracia Cristiana en el 'área chica' de la posdictadura chilena. Prácticas políticas y relaciones clientelares en una comuna chilena", Íconos FLACSO-Ecuador, 60, 2018, 153-163.

Luján y Pérez, "Cercanía, favor, lealtad. Clientelismo en dos municipalidades chilenas", Sociológica, 33, 94, México D.F., 2018, 235-268.

Juan Pablo Luna, "Segmented party-voter linkages in Latin America: the case of the UDI", Journal of Latin American studies, 42, 2010, 325-356.

Rodrigo, Mardones, "Descentralización y transición en chile", Revista de Ciencia política, 26, 1, Santiago, 2006. [citado 2018-11-01], pp.03-24. Disponible en:

$<$ https://scielo.conicyt.cl/scielo.php?script $=$ sci_arttext\&pid=S0718-

090X2006000100001\&lng=es\&nrm=iso >. ISSN 0718-090X.

http://dx.doi.org/10.4067/S0718-090X2006000100001. 
Ortiz y Valenzuela, "Chile, un siglo de pugna por la democratizacio $\square$ n de las regiones. Representacio $\square$ n minimizada y centralismo transversal”, Estudios Pol $\square$ ticos, 52, 2018, pp. 36-56, disponible en: http://www.scielo.org.co/pdf/espo/n52/0121-5167-espo-52-00036.pdf

Aníbal, Pérez, "Clientelismo político, neoliberalismo y la Concertación: El guatón Pinto en el municipio de Valparaíso, 1990-1996”, Divergencia, 2, 3, Valparaíso, 2013, 89-113.

Pérez, “¿UDI popular? Los campamentos y el respaldo electoral-popular de derecha. El caso de Virginia Reginato en Viña del Mar (2008-2013)”, Irquierdas, 21, Santiago 2014, 1-30.

Pérez, "Más allá de la excepcionalidad. Clientelismo político en Chile: debates, antecedentes históricos y algunos rasgos generales en el tiempo presente", en Itinerarios políticos contemporáneos en Argentina, Brasil, Chile y Uruguay, compilado por Pinillos, C.; Cavarozzi, M. y Mella Polanco, M. UNR Editora, Rosario, 161-182.

Peter, Siavelis, "The Hidden Logic of Candidate Selection for Chilean Parliamentary Elections", Comparative Politics, 34, 4, New York, 202, 419-438.

Alfredo, Rehren, "El impacto de las poli $\square$ ticas autoritarias a nivel local: implicancias para la consolidacio $\square$ n democra $\square$ tica en Chile", Santiago, Estudios Pu blicos, 44, 1991.

Verónica, Valdivia, "Al rescate del municipio. La síntesis ideológica de la dictadura pinochetista", Observatorio Latinoamericano, Dossier Chile, Buenos Aires, 2011.

Valdivia, "La alcaldía de Joaquín Lavín y el lavinismo político en el Chile de los noventa", Historia Política, Buenos Aires, 2012, disponible en: < http://historiapolitica.com/datos/biblioteca/chile_ ortizdezarate.pdf $>$-.

Valdivia, "El Santiago de Ravinet. Despolitización y consolidación del proyecto dictatorial en el Chile de los noventa", Historia, 46, Santiago, 2013, 177-219. Disponible en:

https://scielo.conicyt.cl/scielo.php?script=sci_arttext\&pid=S071771942013000100006\&lng=es\&nrm=iso. ISSN 0717-7194. http://dx.doi.org/10.4067/S071771942013000100006 .

Valdivia, "La derecha pinochetista en el post-pinochetismo: auge y crisis del lavinismo 2000-2004", Revista Estudos Ibero-Americanos, 42, 2, Rio Grande do Sul, 2016, 694-723.

Valdivia, "La alcaldización de la política en la post dictadura pinochetista. Las comunas de Santiago, Las Condes y Pudahuel”, Irquierdas 38, Santiago, 2018, 113-140.

Valenzuela y Yévenes, “Aproximación al concepto de cooptación política: la maquinaria presicrática y sus formas", Polis, 14, 40, 2015, pp. 469-488, disponible en:

https://scielo.conicyt.cl/pdf/polis/v14n40/art22.pdf.

Esteban, Valenzuela, "Despoder y progresismo federalistafraterno para superar la izquierda presicrática", Polis, 16, 46, 2017, pp. 127-148, disponible en: https://scielo.conicyt.cl/pdf/polis/v16n46/0718-6568polis-16-46-00127.pdf. 